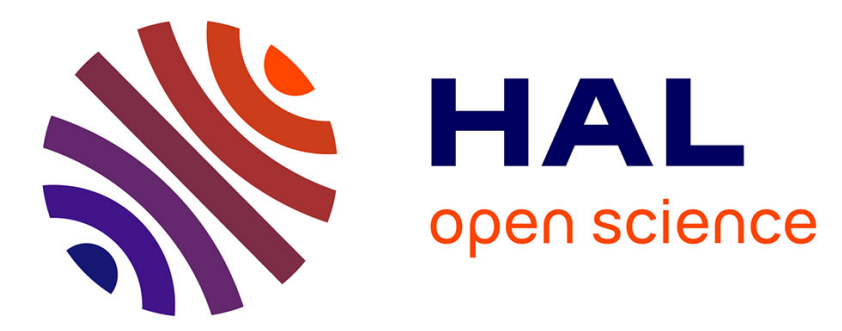

\title{
How does particle size influence caking in lactose powder?
}

Mélanie Carpin, Hans Bertelsen, A. Dalberg, J.K. Bech, Jean Risbo, Pierre

Schuck, Romain Jeantet

\section{- To cite this version:}

Mélanie Carpin, Hans Bertelsen, A. Dalberg, J.K. Bech, Jean Risbo, et al.. How does particle size influence caking in lactose powder?. Journal of Food Engineering, 2017, 209, 10.1016/j.jfoodeng.2017.04.006 . hal-01513287

\section{HAL Id: hal-01513287 \\ https://hal.science/hal-01513287}

Submitted on 24 Apr 2017

HAL is a multi-disciplinary open access archive for the deposit and dissemination of scientific research documents, whether they are published or not. The documents may come from teaching and research institutions in France or abroad, or from public or private research centers.
L'archive ouverte pluridisciplinaire HAL, est destinée au dépôt et à la diffusion de documents scientifiques de niveau recherche, publiés ou non, émanant des établissements d'enseignement et de recherche français ou étrangers, des laboratoires publics ou privés.

\section{다(1)(2)}

Distributed under a Creative Commons Attribution - ShareAlikel 4.0 International 


\title{
How does particle size influence caking in lactose powder?
}

\author{
M. Carpin a, b, c, H. Bertelsen ${ }^{\text {a }}$, A. Dalberg ${ }^{\text {a }}$, J.K. Bech ${ }^{\text {a }}$, J. Risbo ${ }^{\text {b }}$, P. Schuck ${ }^{\text {c, }}$, R. Jeantet ${ }^{\text {c }}$ \\ a Arla Foods Ingredients Group P/S, 6920 Videbæk, Denmark \\ ${ }^{\mathrm{b}}$ Department of Food Science, University of Copenhagen, 1958 Frederiksberg C, Denmark \\ c STLO, UMR 1253, INRA, Agrocampus Ouest, 35000 Rennes, France
}

\section{A R T I C L E I N F O}

\section{Article history:}

Received 29 October 2016

Received in revised form

29 March 2017

Accepted 5 April 2017

Available online $\mathrm{xxx}$

\section{Keywords:}

Crystalline lactose

Caking

Particle size distribution

Moisture sorption

Ring shear tester

\begin{abstract}
A B S T R A C T
Particle size distribution (PSD) is known to influence product properties such as flowability and compressibility. When producing crystalline lactose, different steps can affect the PSD of the final powder. The aim of this study was to investigate the influence of PSD on caking and the mechanisms involved. Smaller particles showed higher moisture sorption and a greater caking tendency, measured by dynamic vapor sorption and ring shear testing, respectively. Therefore, moisture sorption isotherms appeared as a valuable tool to predict the effect of PSD on humidity caking, as confirmed by the results of ring shear testing. Controlling the amount of fines, characterized by a higher content of impurities, a larger specific surface area and a broader span of the PSD, was found critical to limit caking. More precisely, both the total surface area and the span of the PSD require close attention as they can significantly influence humidity and mechanical caking.
\end{abstract}

(c) 2017 Elsevier Ltd. All rights reserved.

\section{Introduction}

Among the whey-derived ingredients, lactose powder production is currently increasing significantly, with a production of nearly 1.26 million tonnes in 2013 and 1.5 million tonnes expected for 2017 (Affertsholt and Fenger, 2013). The numerous applications include e.g. dairy products, confectionery, baked goods and drugs (Lifran et al., 2000). Lactose powder has been produced since the beginning of the 20th century with the yield in focus (Paterson, 2009). The various applications in the food and pharmaceutical industries have led to different levels of quality requirements (Holsinger, 1988). However, these requirements have become stronger over the past decade with the increasing demand for infant formulae. Lactose is indeed the main ingredient in infant formulae as it provides an important source of carbohydrates to match the composition of human milk. Nowadays, quality is an essential differentiation factor in the highly competitive dairy market. One of the product parameters which lactose producers still strive to control to ensure constant quality is the particle size distribution (PSD) of the powder.

\footnotetext{
* Corresponding author.

E-mail addresses: melanie.carpin@arlafoods.com (M. Carpin), hans.bertelsen@ arlafoods.com (H. Bertelsen), anders.dalberg@arlafoods.com (A. Dalberg), jens. kristian.bech@arlafoods.com (J.K. Bech), jri@food.ku.dk (J. Risbo), pierre.schuck@ inra.fr (P. Schuck), romain.jeantet@agrocampus-ouest.fr (R. Jeantet).
}

Particle size distribution is a very important characteristic as it governs several product properties (Ortega-Rivas, 2008) such as density, compressibility (Barbosa Canovas et al., 1987), flowability (Juliano and Barbosa-Cánovas, 2010), segregation (BarbosaCanovas et al., 1985), rehydration (Gaiani et al., 2007), etc. However, obtaining the right PSD is often a challenge. The crystallization step is crucial for this purpose but by no means straightforward given the complex physicochemical processes involved (Schuck, 2011). Downstream, the PSD can be modified unintentionally (e.g. by particle attrition) or intentionally (e.g. by milling).

Caking, i.e. the unwanted agglomeration of powder particles observed as lumps of various sizes and hardness, is another product property which can be influenced by the PSD of the powder (Rogé and Mathlouthi, 2000). Caking has been an issue in numerous powder handling factories for many years and still leads to significant economic loss. The main caking mechanisms in food powders have recently been reviewed by Carpin et al. (2016). Briefly, the first mechanism, i.e. amorphous caking, involves the creation of viscous flow of amorphous material between particles as a result of an increase in temperature beyond the glass transition temperature $\left(T_{g}\right)$. Moisture can plasticize the material and decrease $T_{g}$. Humidity caking is the other mechanism in which moisture plays a critical role. When the relative humidity $(\mathrm{RH})$ of the air surrounding a crystalline material increases, water molecules are indeed adsorbed onto the particle surface and can form liquid bridges between particles. If the $\mathrm{RH}$ exceeds the deliquescence relative humidity 
(DRH) of the material, a phase transition from solid to liquid state takes place, leading to a dramatic increase in the amount of moisture adsorbed. The third mechanism, i.e. mechanical caking, is rather an aggravating factor and can dramatically intensify the two above mentioned mechanisms. Inter-particle interactions are indeed increased when particles come closer to each other, for example as a result of compression.

If the PSD is modified, for example due to changes in the crystallization process, how will the caking tendency of the final powder be impacted? This question frequently arises in the powder handling industries and the answer is not straightforward. Mathlouthi and Rogé (2003) investigated the effect of particle size on moisture sorption and caking of sucrose. The higher the amount of fine particles $(<250 \mu \mathrm{m})$ added to a standard sugar sample, the more sorption was recorded. The particle cohesiveness was found to increase with a decreasing particle size. Fine particles had moderate flow as measured with a Jenike shear cell. This result was explained by their small size and increased hygroscopicity. In addition, Provent et al. (1993) reported that the main cause for caking of a particular pharmaceutical powder was the particle size. By mixing coarse and fine particles in different ratios, they showed that caking was affected by both the total surface area of the powder and the distribution of particle sizes. However, these studies were performed on powders other than lactose, and one could question if the results are still valid for this latter compound. For example, impurities are known to influence the caking behavior of a given powder (Carpin et al., 2017). It is therefore worth investigating the caking mechanisms specific to the lactose powder.

Listiohadi et al. (2005) investigated the effect of milling on the caking behavior of lactose. The hardness of the powder cakes was found to increase for a smaller particle size but moisture sorption was not affected by the particle size. More recently, Modugno et al. (2015) published a study on the influence of the PSD on lactose caking. They sieved the lactose powder to obtain different size classes which were subjected to caking tests. They reported that lactose crystals with a $d 50$ smaller than $300 \mu \mathrm{m}$ could cake easily if the water content was higher than 3\%: they explained their result by a greater number of liquid bridges in the small size classes compared to the large size classes. However, this result cannot be applied to dried lactose powders for which the water content is usually below $0.5 \%$ (Hourigan et al., 2013). Moreover and as in most studies, the span of the size classes was not taken into account, which can greatly affect the packing density of the powder and thereby the number of liquid bridges. Therefore, even though articles have been published on the subject, it remains difficult to assess how the PSD influences caking of a given powder. The aim of the present study was therefore to investigate the influence of the PSD on caking of crystalline lactose and the mechanisms involved. The expected results should provide a clearer picture of what needs to be measured and controlled in order to limit caking.

\section{Materials and methods}

\subsection{Production of lactose powders on a pilot scale}

Decalcified and decolored ultrafiltered (UF) whey permeate was obtained from Arla Foods Ingredients (Viby J, Denmark). The solids content was raised to $60 \%$ in a Centritherm CT2 evaporator (Flavourtech, Griffith, Australia). For lactose crystallization control, the concentrate was cooled in a tank from $79{ }^{\circ} \mathrm{C}$ to $11^{\circ} \mathrm{C}$ in about $18 \mathrm{~h}$. Then, a Lemitec MD80 laboratory decanter centrifuge (Lemitec GMBH, Berlin, Germany) was used to produce five lactose powders with different washing grades. The slurry was first run through the decanter once without water for a pre-wash (Wash 0). This prewashed slurry was then mixed with water at different water/ lactose slurry w/w ratios: $1 / 3$ (Wash 0.3 ), 1/2 (Wash 0.5), 1/1 (Wash 1) and $2 / 1$ (Wash 2). The different washing grades of the prewashed slurry were run through the decanter once more, and then dried in an Anhydro SFD 47 spin flash dryer (SPX Flow Technology, Søborg, Denmark) with an inlet temperature of $105 \pm 2{ }^{\circ} \mathrm{C}$ and an outlet temperature of $85 \pm 3{ }^{\circ} \mathrm{C}$. Finally, the powders were packaged in two layers of plastic bags and a Kraft paper bag before transportation to the analysis laboratory where they were sieved and poured into airtight plastic containers of various sizes to minimize the headspace. The powders were stored at $20^{\circ} \mathrm{C}$ prior to analysis.

\subsection{Sieving}

The lactose powders of different washing grades were sieved through a series of standard testing sieves $(80,160,250,355$ and $500 \mu \mathrm{m}$ ) stacked in a sieve shaker (Retsch sieve shaker AS 200, Retsch GmbH, Haan, Germany) to separate them in different size fractions. The sieving was performed in batches of $500 \mathrm{~g}$ of powder for $5 \mathrm{~min}$ at a 1 -mm amplitude.

For the investigation of the effect of the span on caking (Section 3.5.), two different size fractions of Wash 0.3 powder were produced by sieving; one by sieving Wash 0.3 through 100 and $355 \mu \mathrm{m}$ sieves and another one by sieving Wash 0.3 through 160 and $250 \mu \mathrm{m}$ sieves.

\subsection{Measurement of particle size}

The PSD of the different size fractions was measured by laser light scattering using a Malvern Mastersizer 2000 equipped with a Scirocco 2000 dry dispersion unit (Malvern Instruments, Worcestershire, UK). The span of the distribution was calculated as

Span $=[(d 90-d 10) / d 50]$,

where the diameters $d 10, d 50$, and $d 90$ represent the particle size at $10 \%, 50 \%$, and $90 \%$ in a cumulative size distribution respectively. The specific surface area was calculated from the surface weighted mean $d_{32}$.

\subsection{Chemical composition}

Protein and ash content were determined according to the methods described by Schuck et al. (2012). Total nitrogen content determined by Kjeldahl with a 6.38 conversion factor will be designated as protein content. Given the filtration steps in the lactose process, it is, however, unlikely that proteins remain in the final powder. Therefore, impurities formally expressed as protein may more likely be smaller nitrogen containing components such as peptides and amino-acids. Analysis of ash content was carried out in triplicate and the protein content was determined in duplicate.

\subsection{Particle morphology - Scanning Electron Microscopy (SEM)}

The surface morphology of the lactose samples was examined using a Scanning Electron Microscope (SEM, JEOL JCM-6000 NeoScope II, Tokyo, Japan) operating at $15 \mathrm{kV}$. Samples were mounted on an aluminum stub and coated with a thin layer of gold (JEOL JFC-1300 auto fine coater) prior to analysis. The photomicrographs were taken at $\times 400$ magnification.

\subsection{Moisture sorption measurements}

Sorption isotherms of powders were obtained with a Dynamic Vapor Sorption (DVS) Advantage (Surface Measurement Systems 
Ltd., London, UK) equipped with a Cahn microbalance. The experiments were carried out in duplicate at a constant temperature $\left(25{ }^{\circ} \mathrm{C}\right)$ using a nitrogen flow rate of 200 standard $\mathrm{cm}^{3} \mathrm{~min}^{-1}$. Approximately $40 \mathrm{mg}$ of powder was subjected to ramping of $\mathrm{RH}$ from $0 \%$ to $95 \%$ in $10 \%$ RH steps with water as solvent. Equilibrium was considered to be reached if the rate of change in mass was less than $0.0002 \% \cdot \mathrm{min}^{-1}$.

\subsection{Quantification of caking}

Caking, also known as time consolidation, was measured with a ring shear tester (RST-XS, Schulze-Schüttgutmesstechnik, Wolfenbüttel, Germany). The measurement procedure has been described in detail by Schulze (2008). First, the yield locus of each powder was measured for a normal stress at preshear $\sigma_{\text {pre }}$ corresponding to a consolidation stress $\sigma_{\mathrm{c}}$ of approx. $9.3 \mathrm{kPa}$. This value was chosen to simulate powder consolidation at the bottom of a flexible intermediate bulk container (FIBC), also called Big Bag. Three points of incipient flow were used to draw the yield locus. Once the initial yield locus was established, the powder was preconditioned using the same $\sigma_{\text {pre }}$ as above and stored at $20^{\circ} \mathrm{C}$ and $60 \% \mathrm{RH}$ for four days. A temperature and humidity data logger was used to check the storage conditions. Loads of $2 \mathrm{~kg}$ (corresponding to a consolidation stress of $9.3 \mathrm{kPa}$ ) were applied to the samples for the duration of storage. After storage, the samples were sheared to obtain the time yield locus. From this, the unconfined yield strength $\sigma_{1}$ and the ratio of $\sigma_{\mathrm{c}}$ to $\sigma_{1}$, called $f f c$, were identified. The larger the $f f c$ was, the better the powder flowed. By definition, a sample with an $f f c$ lower than 1 was considered to be caked (Jenike, 1964). For each powder, the $f f c$ was measured in triplicate, with the exception of the investigation of the effect of the span on caking (Section 3.5.), where the $f f c$ was measured in duplicate.

\subsection{Solid-state Nuclear Magnetic Resonance (NMR)}

13C NMR spectra were obtained using proton decoupling, magic angle spinning (MAS) and cross polarization (CP). The spectra were recorded on a Bruker Avance I WB $300 \mathrm{MHz}$ (7T) instrument (Bruker, Billerica, USA) at ambient temperature according to the method described by Gustafsson et al. (1998), with the following parameters: spinning rate $5 \mathrm{kHz}$, contact time $2 \mathrm{~ms}$, acquisition time $147 \mathrm{~ms}$, sweep widths $2190 \mathrm{ppm}$ and delay between pulses of 3 s. For each spectrum, about 150,000 transients were cumulated with $49 \mathrm{k}$ data points. The spectra were referenced to trimethylsilane (TMS).

\section{Results and discussion}

\subsection{Particle size distribution (PSD)}

The division between the different size classes obtained by sieving the two extreme washing grades (Wash 0 and Wash 2) was noticeably different (Fig. 1). Particles were generally bigger in Wash 0 , which can be explained by the presence of agglomerates, visible on the sieve in the fraction above $500 \mu \mathrm{m}$. These agglomerates may be structured by liquid bridges, favored by the presence of fines $(\mathrm{x}<80 \mu \mathrm{m})$; the dissolution of the fines upon washing, as indicated by the low amount of remaining fines in Wash 2, led to a narrowed PSD with very few particles over $355 \mu \mathrm{m}$. In line with these observations, the general trend for all washing grades was that a decreasing washing grade led to bigger particles (data not shown). Thus, apart from crystallization (Schuck, 2011), washing is another important processing step that must be controlled in order to obtain a given PSD. Moreover, the particle size should not be neglected when investigating the effect of the washing grade on a

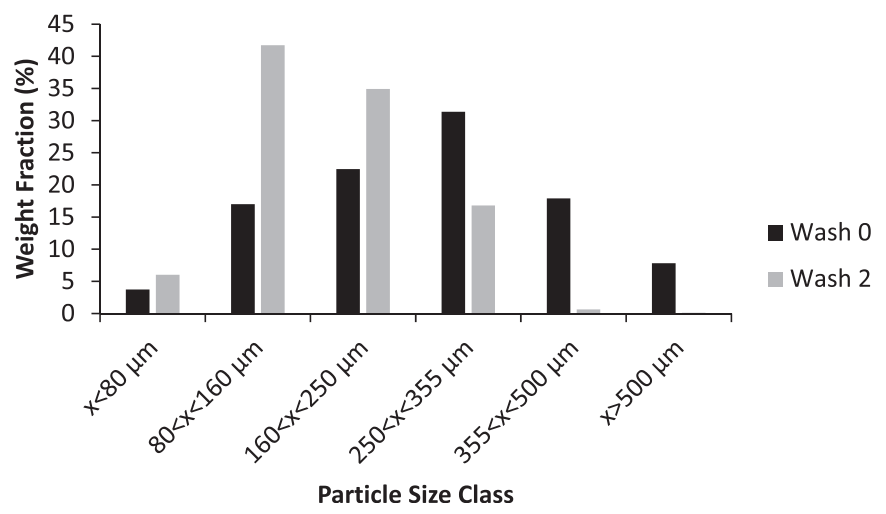

Fig. 1. Particle size distributions of Wash 0 and Wash 2 lactose powders sieved to separate $80,160,250,355$ and $500 \mu \mathrm{m}$ fractions.

given powder parameter, such as for example caking.

\subsection{Chemical composition}

The different particle size fractions were analyzed separately for their impurity content. Impurities consisted in non-lactose components, mainly minerals and nitrogen containing components expressed as proteins, remaining in the powder after crystallization and washing. The fines $(\mathrm{x}<80 \mu \mathrm{m})$ showed a higher content of proteins and ash than the bigger particles in Wash 0, Wash 1 and Wash 2 (Fig. 2). Wash 0 presented a minimum content of impurities in the size fraction $250<\mathrm{x}<355 \mu \mathrm{m}$; above this size fraction, increasing the particle size resulted in a higher content of impurities (Fig. 2). In Wash 1 and Wash 2, the general trend was a decrease in the impurity content with a larger particle size. Moreover, as expected, a smaller specific surface area was measured for larger particles (Fig. 2).

In general, and with the exception of the larger size fractions of Wash 0 , the evolution of impurity content with the particle size followed the one of the specific surface area. This indicates that impurities are likely to be located mostly on the surface of the particles. In Wash 0 , the agglomeration of impurity containing fines together or on a larger crystal may explain the greater amount of impurities in the size fractions $\mathrm{x}>355 \mu \mathrm{m}$. As these agglomerates were most likely only present in the lowest washing grade Wash 0 (Fig. 1), they may explain the different evolution of impurity content with particle size for Wash 0 compared to the other washing grades (Fig. 2). The results indicate that the fine fraction should be given attention as it can greatly influence the level of impurities in the powder. Crystallization is an important processing step to control the amount of small crystals. However, small particles are often fragments of bigger crystals which are damaged during processing steps (Mathlouthi and Rogé, 2003) such as rotary drying in a spin flash dryer used in the present study. Considering the industrial process for lactose production, air transport between silos can for example be harsh to the particles which may be altered by attrition. In addition, milling is obviously a processing step which affects the particle size distribution of the final product (Hourigan et al., 2013).

\subsection{Aspect of the fines}

Microscopic observations of the fine particles can help identify whether these are whole but small crystals or fragments of bigger crystals. Scanning electron microscopes of Wash 0 and Wash 2 powders revealed differences in the agglomeration propensity of the fines (Fig. 3A and B). Wash 0 showed agglomerated particles 

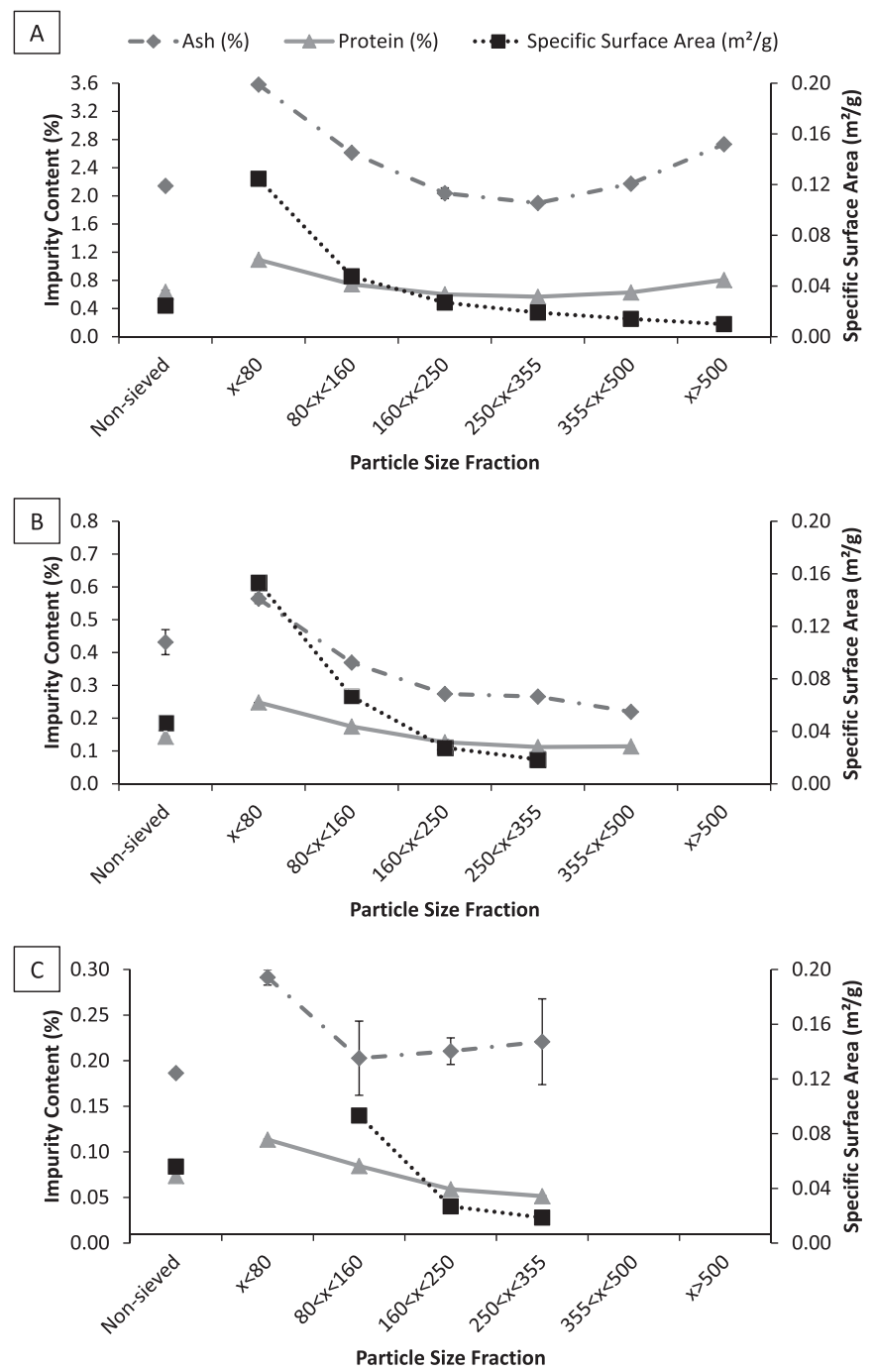

Fig. 2. Impurity content (either protein or ash content; left axis) and specific surface area (right axis) of lactose powders as a function of the particle size class: (A) Wash 0 ; (B) Wash 1; (C) Wash 2. Results are given as average \pm standard deviation (represented by the error bars). Number of repetitions $=4$ for specific surface area, 3 for ash, and 2 for proteins.

(Fig. 3A) as expected from the particle size distribution (Fig. 1). In contrast, small particles in Wash 2 were a mix of well-formed crystals and agglomerates. Very small fragments were also present (Fig. 3B). For both powders, the agglomerated fragments were

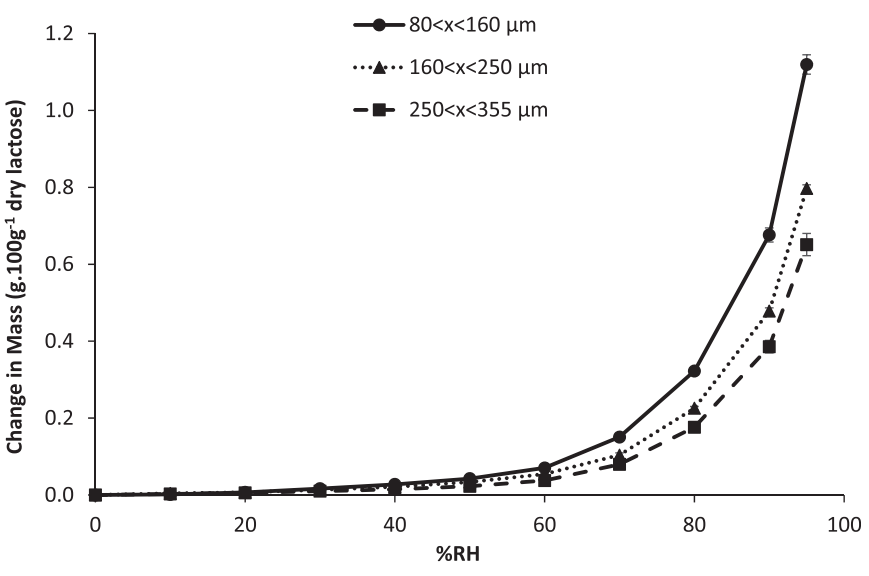

Fig. 4. Moisture sorption isotherms of lactose powder Wash 2 for three different particle size fractions: $80<\mathrm{x}<160 \mu \mathrm{m}$ : circles; $160<\mathrm{x}<250 \mu \mathrm{m}$ : triangles: $250<\mathrm{x}<355 \mu \mathrm{m}$ : squares.

likely to originate from the surface of bigger crystals. Assuming that impurities were mainly concentrated on the crystal surface, these fragments thereby increased the overall impurity content of the fine fraction. A suitable technique which could distinguish between the composition of the surface and the inner part of a lactose crystal could confirm this hypothesis. For example, the surface composition of several milk powders, characterized by X-ray photoelectron spectroscopy (XPS), was found to differ from their bulk composition in lactose, proteins and fat (Murrieta-Pazos et al., 2012).

\subsection{Moisture sorption}

The difference in moisture sorption behavior depending on the size fraction was significant (Fig. 4). The final amount of water sorbed (at 95\% RH) indeed increased for the smaller particles $(80<\mathrm{x}<160 \mu \mathrm{m})$ compared to the medium $(160<\mathrm{x}<250 \mu \mathrm{m})$ and bigger $(250<\mathrm{x}<355 \mu \mathrm{m})$ particles by $40 \%$ and $72 \%$, respectively.

When the ambient $\mathrm{RH}$ increases, three mechanisms of watersolid interactions can be considered for the crystalline lactosewater system, i.e. adsorption of water molecules on crystal surface, capillary condensation and deliquescence (Mauer and Taylor, 2010). As moisture sorption occurs primarily on the surface, the larger specific surface area associated with smaller particles (Fig. 2) is consistent with a higher sorption behavior. Likewise, such an increase in moisture sorption was measured for smaller particles of glass beads (Stoklosa et al., 2012) and sucrose (Mathlouthi and Rogé, 2003) compared to bigger counterparts.

Moreover, capillary condensation occurs in pores between
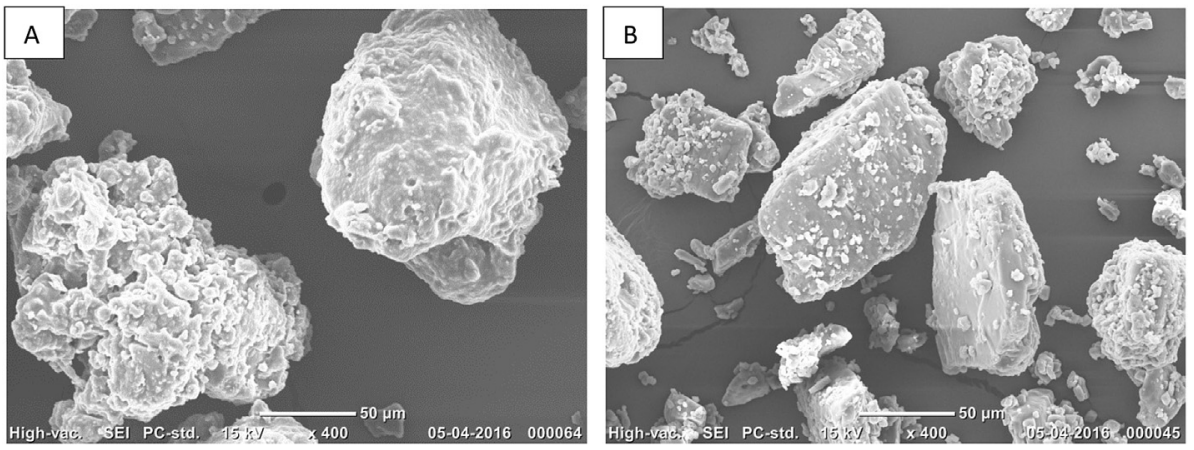

Fig. 3. SEM images showing small particles of different washing grade lactose powders: (A) Wash 0 ; (B) Wash 2 . 


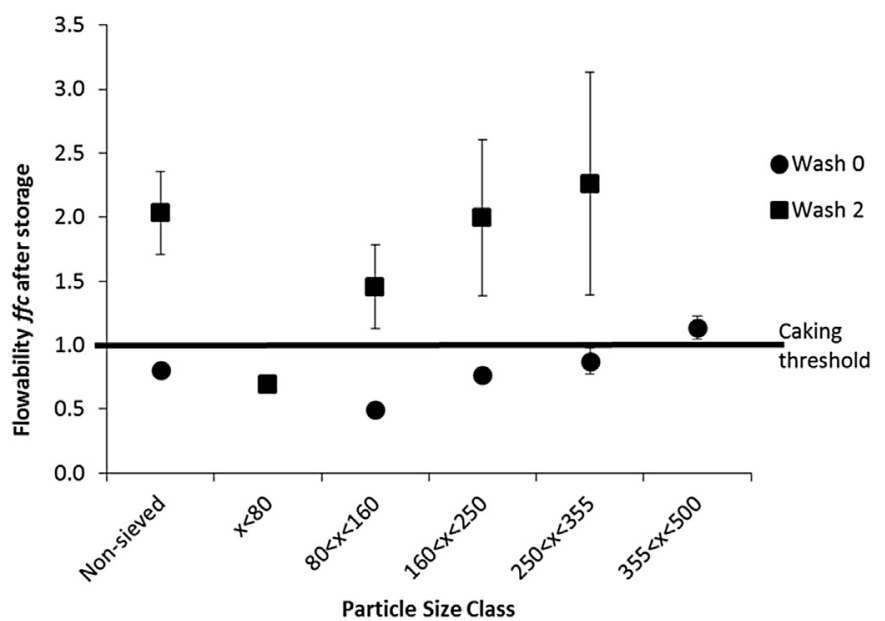

Fig. 5. Flowability ffc of lactose powders Wash 0 (circles) and Wash 2 (squares) as a function of particle size class after storage for four days at $60 \% \mathrm{RH}$ and $20{ }^{\circ} \mathrm{C}$ and under a consolidation stress of $9.3 \mathrm{kPa}$.

adjacent particles. Using the Kelvin equation, it is possible to predict the critical capillary radius below which all capillaries will be full of water at a given water activity and temperature (Billings et al., 2006). The size distribution of the pores is expected to depend both on the average particle size as smaller particles give smaller pores, but also on the span of the particle size distribution as powder with a larger span can be compacted to a higher packing density and thus a structure with smaller pores (Bronlund and Paterson, 2004). The PSD of the different size fractions of Wash 2 powder showed a broader span value (Eq. (1)) for the fraction $80<\mathrm{x}<160 \mu \mathrm{m}$ compared to the fractions $160<\mathrm{x}<250 \mu \mathrm{m}$ and $250<\mathrm{x}<355 \mu \mathrm{m}: 1.56,0.88$ and 0.73 respectively. This broader span certainly contributes to the higher moisture sorption behavior of the size class $80<\mathrm{x}<160 \mu \mathrm{m}$.

Finally, pure crystalline lactose is characterized by a very low hygroscopicity, with a deliquescence relative humidity (DRH) value of 95\% (Salameh et al., 2006). However, for water-soluble crystalline solids it has been shown that impurities can increase moisture sorption below DRH and reduce the DRH value (Guerrieri et al., 2007; Tereshchenko, 2015). The higher content of impurities in the smaller particles (Fig. 2), especially if these impurities are located on the surface, is thus likely to influence the shape of the sorption isotherm.

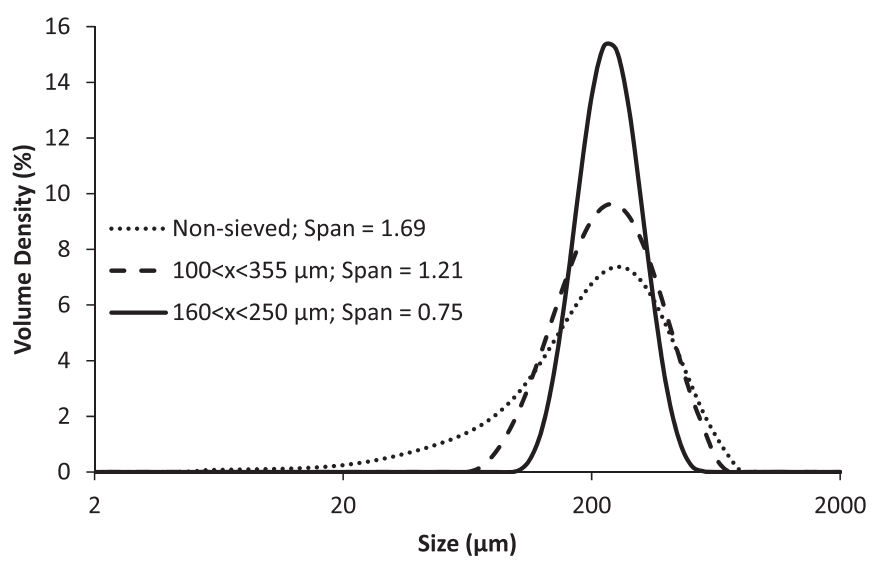

Fig. 6. Particle size distributions of different size fractions (non-sieved, $100<\mathrm{x}<355 \mu \mathrm{m}$ and $160<\mathrm{x}<250 \mu \mathrm{m}$ ) of lactose powder Wash 0.3 .
In summary, the observation of increasing moisture sorption for the smaller size fraction can be explained by a larger surface area, a higher level of impurities and smaller capillaries due to a lower voidage fraction and due to a broader span of the size distribution.

\subsection{Caking tendency}

The caking tendency of the different size fractions of the least (Wash 0) and most washed (Wash 2) powders from the pilot trial was measured with a ring shear tester (Fig. 5). For both powders, it was clear that the smaller particles showed poorer flowability after storage (i.e. lower $f f c$ value) and thus a higher caking tendency. It was even possible to exceed the caking threshold by selecting the right particle size fraction and thereby prevent the powder from caking under the chosen storage conditions. For a given powder, the non-sieved fraction had an intermediate caking tendency compared to the sieved fractions. The results for the caking tendency of the different size fractions of Wash 1 showed the same trend (data not shown).

The results for the caking measurements were consistent with the moisture sorption isotherms showing higher sorption for smaller particles. Humidity caking is therefore a critical mechanism to consider for caking in lactose powder under the selected conditions. Similarly, Paterson and Bronlund (2009) also concluded on a capillary condensation mechanism leading to significant liquid bridging in crystalline lactose powder.

Moreover, sugar dust from a sugar factory has been reported to contain amorphous material originating from the surface of sucrose crystals dried at high temperatures in a short time (Mathlouthi and Rogé, 2003). These fines were shown to adsorb significantly more moisture compared to microcrystals of the same size produced with a special crystallization process. In the present study, different size fractions of Wash 0 powder were analyzed by solid-state NMR but the amount of amorphous material was below detection limit (data not shown). Thus, amorphous material in the fines is probably present at too low levels to trigger amorphous caking, i.e. viscous flow of material to contact points. However, even in low levels, amorphous material can still promote moisture sorption and thus contribute to caking. Fragments of bigger particles surface among the fines, as revealed by SEM images (Fig. 3), should therefore be closely controlled as they can contain amorphous material.

The third mechanism reported in the literature for caking in food powders is mechanical caking (Carpin et al., 2016). This mechanism is highly influenced by the PSD of the powder through the number of possible contact points. As smaller particles are known to create more contact points than the bigger counterparts for the same volume of powder, mechanical caking takes part in the greater caking tendency of the smaller particles (Fig. 5). However, Bronlund and Paterson (2004) measured more moisture sorption and thereby a greater possibility of caking in unmilled lactose compared to the milled powder; they explained this difference by a wider PSD in unmilled lactose. The $d 50$, i.e. the mean particle size of the distribution, is therefore not the only parameter that should be taken into consideration when assessing the effect of a change in the PSD on caking.

In order to investigate the influence of the span, three different size fractions ( $160<\mathrm{x}<250 \mu \mathrm{m}, 100<\mathrm{x}<355 \mu \mathrm{m}$ and non-sieved) of the same lactose powder with very similar $d 50$ values $(243 \pm 11 \mu \mathrm{m})$ were subjected to caking measurements. The PSD of the three size fractions was measured to verify that they had different span values but similar $d 50$ values (Fig. 6). A lactose powder with an intermediate washing grade (i.e. Wash 0.3 ) was used for these time consolidation experiments. This powder was chosen to allow moderate to strong caking to take place in the powder and thereby a differentiation of the samples while avoiding 


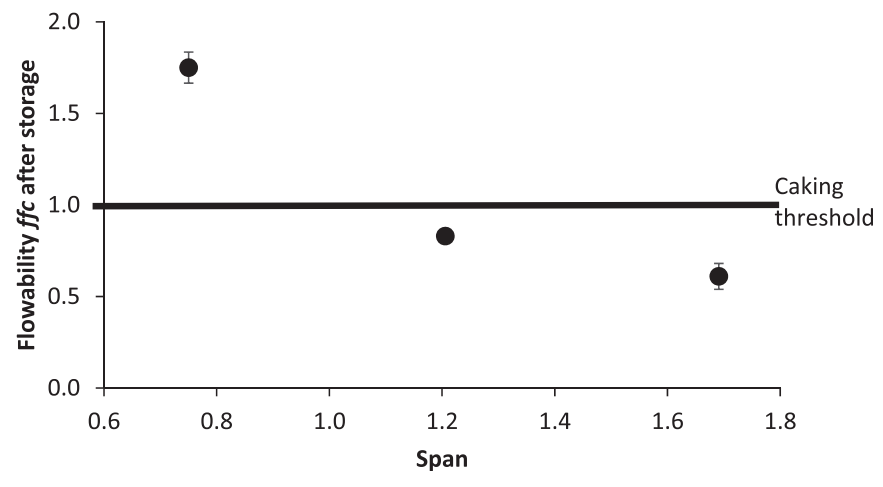

Fig. 7. Flowability $f f c$ of different size fractions of lactose powder Wash 0.3 as a function of the span of the particle size distribution. The size fractions were $160<\mathrm{x}<250 \mu \mathrm{m}, 100<\mathrm{x}<355 \mu \mathrm{m}$ and non-sieved, with the span being $0.75,1.21$ and 1.69 respectively. The measured $d 50$ were $249 \mu \mathrm{m}, 249 \mu \mathrm{m}$ and $230 \mu \mathrm{m}$ respectively. The $f f c$ was measured after storage for four days at $60 \% \mathrm{RH}$ and $20{ }^{\circ} \mathrm{C}$ and under a consolidation stress of $9.3 \mathrm{kPa}$.

a strong caking of all samples.

Fig. 7 shows that for powders with similar $d 50$, a broader span of the size distribution clearly led to a stronger caking tendency, in agreement with the observations of Bronlund and Paterson (2004). The numerous contact points associated with a wider PSD allow more interactions between particles and thereby increase the possibility of mechanical caking and humidity caking by capillary condensation, as explained in Section 3.4.

The PSD of food powders can be difficult to control in industrial settings because of the many processing steps which can affect it. However, the results presented in this study clearly show the importance of controlling the PSD to be able to prevent caking in the final product. In order to assess the effect of changes in PSD on the caking tendency of the product, it is crucial to consider both the specific surface area of the powder and the span of the size distribution as they influence caking in different ways. Indeed, Provent et al. (1993) reported that mixing coarse and fine particles in a powder might lead to critical concentrations of fines for which the risk of caking was greatest. It might therefore be helpful to shift the size distribution slightly towards bigger particles in order to remove part of the fines. As shown in this study, the presence of more fines in a powder leads to a larger specific surface area and more impurities, thus increasing the amount of water adsorbed and decreasing the DRH value. Furthermore, a broader span promotes capillary condensation and mechanical caking. Given the importance of the humidity caking mechanism in a crystalline powder, the moisture sorption isotherm is definitely a valuable tool to help predicting the effect of the PSD on caking.

\section{Conclusions}

Smaller particles showed higher moisture sorption and a greater caking tendency compared to bigger counterparts. The larger specific surface area and higher content of impurities associated with the smaller particles increase the possibility of humidity caking. It is therefore essential to control the amount of fines, which was found to depend on the washing grade. More precisely, attention should be paid to both the span of the PSD and the specific surface area of the powder as these two parameters influence mechanical caking through the number of contact points and humidity caking through moisture sorption, capillary condensation and deliquescence.

\section{Acknowledgments}

This work was partially funded by Innovation Fund Denmark.
The authors wish to thank Morten Nielsen for his great help in conducting the trial. We are grateful to Betina Mikkelsen and Anne Dolivet for showing us how to conduct SEM imaging and all the physicochemical characterization analyses.

\section{References}

Affertsholt, T., Fenger, M., 2013. Whey Book 2014-The Global Market for Whey and Lactose Ingredients 2014-2017.

Barbosa Canovas, G.V., Malave-Lopez, J., Peleg, M., 1987. Density and compressibility of selected food powders mixtures. J. Food Process Eng. 10, 1-19. http:/ dx.doi.org/10.1111/j.1745-4530.1987.tb00001.x.

Barbosa-Canovas, G., Malave-Lopez, J., Peleg, M., 1985. Segregation in food powders. Biotechnol. Prog. 1, 140-146.

Billings, S.W., Bronlund, J.E., Paterson, A.H.J., 2006. Effects of capillary condensation on the caking of bulk sucrose. J. Food Eng. 77, 887-895. http://dx.doi.org/ 10.1016/j.jfoodeng.2005.08.031.

Bronlund, J., Paterson, T., 2004. Moisture sorption isotherms for crystalline, amorphous and predominantly crystalline lactose powders. Int. Dairy J. 14, 247-254. http://dx.doi.org/10.1016/S0958-6946(03)00176-6.

Carpin, M., Bertelsen, H., Bech, J.K., Jeantet, R., Risbo, J., Schuck, P., 2016. Caking of lactose: a critical review. Trends Food Sci. Technol. 53, 1-12. http://dx.doi.org/ 10.1016/j.tifs.2016.04.002.

Carpin, M., Bertelsen, H., Dalberg, A., Roiland, C., Risbo, J., Schuck, P., Jeantet, R., 2017. Impurities enhance caking in lactose powder. J. Food Eng. 198, 91-97. http:/ dx.doi.org/10.1016/j.jfoodeng.2016.11.013.

Gaiani, C., Schuck, P., Scher, J., Desobry, S., Banon, S., 2007. Dairy powder rehydration: influence of protein state, incorporation mode, and agglomeration. J. Dairy Sci. 90, 570-581. http://dx.doi.org/10.3168/jds.S0022-0302(07)71540-0.

Guerrieri, P., Salameh, A.K., Taylor, L.S., 2007. Effect of small levels of impurities on the water vapor sorption behavior of ranitidine HCl. Pharm. Res. 24, 147-156. http://dx.doi.org/10.1007/s11095-006-9134-y.

Gustafsson, C., Lennholm, H., Iversen, T., Nystro, C., 1998. Comparison of solid-state NMR and isothermal microcalorimetry in the assessment of the amorphous component of lactose. Int. J. Pharm. 174, 243-252.

Holsinger, V.H., 1988. Lactose. In: Wong, N., Jenness, R., Keeney, M., Marth, E. (Eds.) Fundamentals of Dairy Chemistry. Springer, US, pp. 279-342. http://dx.doi.org/ 10.1007/978-1-4615-7050-9 6.

Hourigan, J., Lifran, E., Vu, L., Listiohadi, Y., Sleigh, R., 2013. Lactose: chemistry processing, and utilization. In: Smithers, G.W., Augustin, M.A. (Eds.), Advances in Dairy Ingredients. John Wiley \& Sons, Inc., pp. 31-69

Jenike, A.W., 1964. Storage and Flow of Solids. Bulletin 123 of the University of Utah, Salt Lake City.

Juliano, P., Barbosa-Cánovas, G.V., 2010. Food powders flowability characterization: theory, methods, and applications. Annu. Rev. Food Sci. Technol. 1, 211-239. http://dx.doi.org/10.1146/annurev.food.102308.124155.

Lifran, E.V., Hourigan, J.A., Sleigh, R.W., Johnson, R.L., 2000. New wheys for lactose Food Aust. 52, 120-125.

Listiohadi, Y., Hourigan, J., Sleigh, R., Steele, R., 2005. Effect of milling on the caking behaviour of lactose. Aust. J. Dairy Technol. 60, 214-224.

Mathlouthi, M., Rogé, B., 2003. Water vapour sorption isotherms and the caking of food powders. Food Chem. 82, 61-71. http://dx.doi.org/10.1016/S0308-8146(02) 00534-4.

Mauer, L.J., Taylor, L.S., 2010. Water-solids interactions: deliquescence. Annu. Rev. Food Sci. Technol. 1, 41-63. http://dx.doi.org/10.1146 annurev.food.080708.100915.

Modugno, C., Paterson, A.H.J., McLeod, J., 2015. Lactose caking: influence of the particle size distribution and the water content. Proced. Eng. 102, 114-122. http://dx.doi.org/10.1016/j.proeng.2015.01.112.

Murrieta-Pazos, I., Gaiani, C., Galet, L., Calvet, R., Cuq, B., Scher, J., 2012. Food powders: surface and form characterization revisited. J. Food Eng. 112, 1-21. http://dx.doi.org/10.1016/j.jfoodeng.2012.03.002.

Ortega-Rivas, E., 2008. Bulk properties of food particulate materials: an appraisal of their characterisation and relevance in processing. Food Bioprocess Technol. 2, 28-44. http://dx.doi.org/10.1007/s11947-008-0107-5.

Paterson, A.H.J., 2009. Production and uses of lactose. In: McSweeney, P.L.H., Fox, P.F. (Eds.), Advanced Dairy Chemistry. Springer, New York, pp. 105-120. http:// dx.doi.org/10.1007/978-0-387-84865-5.

Paterson, A.H.J., Bronlund, J.E., 2009. The practical implications of temperature induced moisture migration in bulk lactose. J. Food Eng. 91, 85-90. http:// dx.doi.org/10.1016/j.jfoodeng.2008.08.021.

Provent, B., Chulia, D., Cary, J., 1993. Particle size and the caking tendency of a powder. Eur. J. Pharm. Biopharm. 39, 202-207.

Rogé, B., Mathlouthi, M., 2000. Caking of sucrose crystals: effect of water content and crystal size. Zuckerindustrie 125, 336-340.

Salameh, A.K.A., Mauer, L.J.L., Taylor, L.S.L., 2006. Deliquescence lowering in food ingredient mixtures. J. Food Sci. 71, E10-E16. http://dx.doi.org/10.1111/j.13652621.2006.tb12392.x.

Schuck, P., 2011. Lactose and oligosaccharides | Lactose: crystallization. In: Fuquay, J.W., Fox, P.F., McSweeney, P. (Eds.), Encyclopedia of Dairy Sciences. Academic Press, San Diego, pp. 182-195.

Schuck, P., Dolivet, A., Jeantet, R., 2012. Analytical Methods for Food and Dairy Powders. Wiley-Blackwell, Oxford, UK. http://dx.doi.org/10.1002 
9781118307397.

Schulze, D. 2008. Powders and Bulk Solids: Behavior, Characterization, Storage and Flow. Springer Berlin Heidelberg, Berlin, Heidelberg. http://dx.doi.org/10.1007 978-3-540-73768-1.

Stoklosa, A.M., Lipasek, R.A., Taylor, L.S., Mauer, L.J., 2012. Effects of storage conditions, formulation, and particle size on moisture sorption and flowability of powders: a study of deliquescent ingredient blends. Food Res. Int. 49, 783-791. http://dx.doi.org/10.1016/j.foodres.2012.09.034.

Tereshchenko, A.G., 2015. Deliquescence: hygroscopicity of water-soluble crystalline solids. J. Pharm. Sci. http://dx.doi.org/10.1002/jps.24589,

Please cite this article in press as: Carpin, M., et al., How does particle size influence caking in lactose powder?, Journal of Food Engineering (2017), http://dx.doi.org/10.1016/j.jfoodeng.2017.04.006 